$V_{T}$

NCER Working Paper Seriés

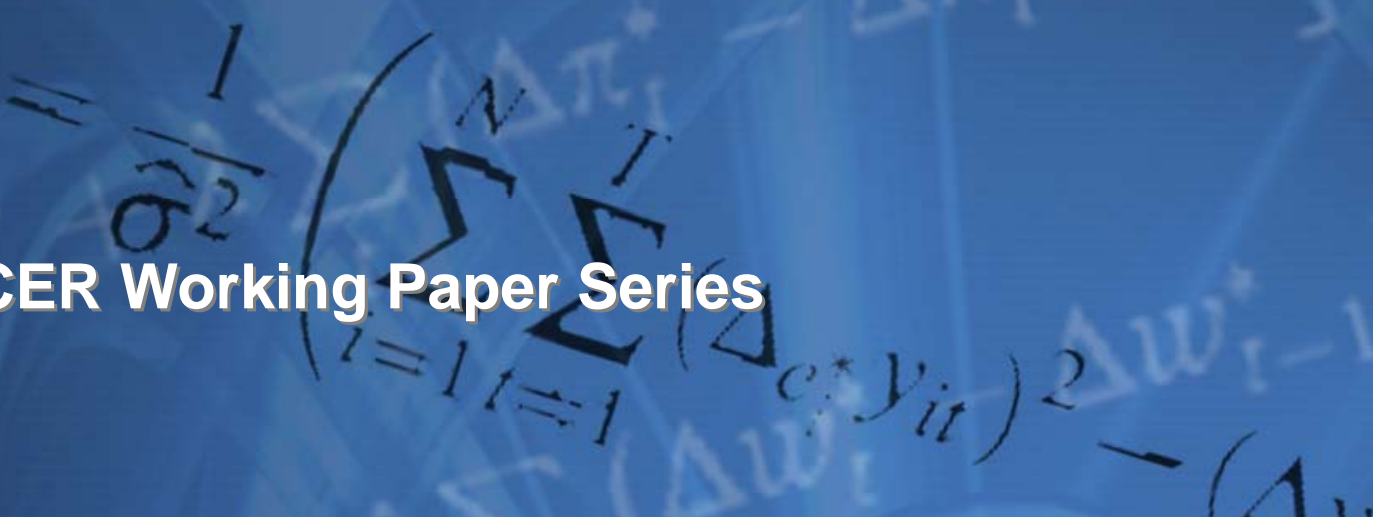

\title{
Substitution Between Managers and Subordinates: Evidence from British Football
}

Sue Bridgewater

Lawrence M. Kahn

Amanda H. Goodall

Working Paper \#51 November 2009

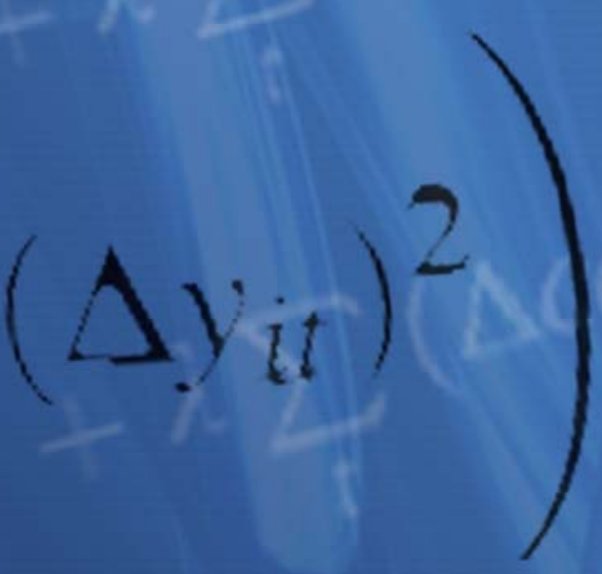


SUBSTITUTION BETWEEN MANAGERS AND SUBORDINATES: EVIDENCE FROM BRITISH FOOTBALL*

\author{
Sue Bridgewater \\ Warwick Business School \\ University of Warwick \\ Lawrence M. Kahn \\ Cornell University, IZA, CESifo, and NCER (Australia) \\ Amanda H. Goodall \\ Warwick Business School \\ University of Warwick
}

November 132009

* Preliminary draft. Comments welcome. 


\title{
SUBSTITUTION BETWEEN MANAGERS AND SUBORDINATES: EVIDENCE FROM BRITISH FOOTBALL
}

\begin{abstract}
We use data on British football managers and teams over the 1994-2007 period to study substitution and complementarity between leaders and subordinates. We find for the Premier League (the highest level of competition) that, other things being equal, managers who themselves played at a higher level raise the productivity of less-skilled teams by more than that of highly skilled teams. This is consistent with the hypothesis that one function of a top manager is to communicate to subordinates the skills needed to succeed, since less skilled players have more to learn. We also find that managers with more accumulated professional managing experience raise the productivity of talented players by more than that of less-talented players. This is consistent with the hypothesis that a further function of successful managers in high-performance workplaces is to manage the egos of elite workers. Such a function is likely more important the more accomplished the workers are -- as indicated, in our data, by teams with greater payrolls.
\end{abstract}

JEL Codes: J24, M51.

Keywords: Productivity, leadership. 


\section{Introduction}

Microeconomic models of the firm typically assume a production function, sometimes with labor inputs disaggregated into managerial and production labor (and perhaps clerical labor as a separate category). Yet little is known about the ways in which managers augment production. For example, do managers directly affect the productivity of their subordinates, and if so, how? Knowledge of such effects is potentially important for studying many issues in economics, including for example wage inequality. Suppose, for instance, that managers are complementary inputs with certain types of labor, such as less skilled workers; for example, less skilled workers may need more supervision or training by managers than more highly skilled workers would. If so, then exogenous increases in the supply of unskilled labor (caused perhaps by immigration from less developed countries) will raise the relative demand for managers, and overall wage inequality will rise by more than one might have thought. Conversely, if the two kinds of labor are substitutes, then the relative demand for managers would fall, reducing the rise in wage inequality. For example, it is possible that unskilled workers could take over some basic monitoring functions from management.

Knowledge about the ways in which managers contribute to organizational success is also crucial in the study of human resource management. Researchers in that field are concerned with the roles of managerial expertise and the motivation of subordinates. The same questions that are of interest to applied microeconomists such as the substitutability across factors of production are also important to firms, as they decide on their best strategies for combining managerial and production worker expertise.

The nature of the production relationship between supervisors and subordinates is difficult to study in most settings. Often there are only rather imperfect measures of output, and firm-level data on combinations of various kinds of labor inputs are usually hard to obtain. Data on sports leagues can be ideal in this situation because output is 
observable. In the later analysis, we have detailed measures of the qualifications of managers and who their subordinates are.

This paper uses data from British professional football to study the issues of substitution and complementarity between managers and subordinates. We exploit British football data for the 1994-2007 seasons to study whether managers' skills substitute for or complement players' skills. Managers' skills are proxied by information on the level at which they played (if they played at all), as well as their degree of experience as managers, while player skills are proxied by the relative payroll (for players) of the team in a given season.

Our strongest findings are for the Premier League (the highest level of competition). We estimate frontier production functions where output is defined as the team's finishing position relation to other teams in the league in a given season. Our findings indicate that other things being equal, managers who played at a higher level raise the productivity of lesser skilled teams by more than that of more highly skilled teams. This finding is consistent with the hypothesis that one of the functions of a highly skilled manager is to teach subordinates some of the skills needed to succeed. The value of this teaching is, according to our results, greater the less skilled the players are, an intuitively plausible result. An additional finding, however, suggests that other things being equal (including the manager's playing ability), managers with more accumulated professional managing experience raise the productivity of more skilled players by more than that of less skilled players. This finding is consistent with the idea that another function of successful managers in high pressure, high performance workplaces may be to manage the egos of the workers involved. This function is likely more important the more accomplished the workers are, as indicated in our data by teams with higher relative payroll levels. Our findings, then, suggest that managerial skills are multidimensional, including instruction as well as an ability to coax peak levels of performance from high 
ability workers. These results may have some relevance to high performance workplaces such as professional law or consulting practices, high tech innovative companies or research universities.

\section{Expectations and Previous Research on Managerial Productivity in Sports}

We seek to understand the impact of managerial expertise in playing soccer on the success of English soccer teams. Managers who were great players may be able to impart skills and insights to the current generation of players, suggesting a positive impact of the manager's prior playing skill on team success. For example, as suggested by Goodall, Kahn and Oswald (2008) in the context of North American professional basketball, this impact may come about through several possible routes:

- Perhaps this is the coach's acquired skill based on the in-depth knowledge of what wins games.

- Perhaps the manager has played for and gained useful skills from great coaches.

- Perhaps some "tenacious personality" factor is at work. What made someone a winner as a player makes him a winner as a coach.

- Maybe this is even something genetic that makes the person a winner.

In football terms, having been a great footballer might be expected to provide several types of expertise which could be useful to the manager.

- Great players might lead by example: "I have achieved this and you are also able to."

- As in the case of basketball just discussed, a great player might be able to demonstrate a particular football skill, or to spot a potentially great player.

- A manager who was a great player may have an understanding of how the game should be played at the highest level. "This is what we are aiming for."

- Players at higher levels may have networks among better clubs. Even if the manager is working at lower level, he might be able to use his name and contacts 
to attract good players, or to get loans from the second string of higher level clubs.

- Perhaps the reputation and credibility of being a great player impresses the players of today.

- All of these might reasonably help top players create a culture and help the manager to become a visionary and inspirational leader who players want to follow.

While better players may indeed make better managers, going in the opposite direction is the possibility that a manager who was a great player may not be able to identify with journeymen players and understand what motivates them. For example, one manager who had, himself, played at the top but managed in lower leagues complained of his players:

“They just couldn't do the things that I was used to players being able to do. We would work on something in training, for example how to defend a corner, and everyone would know who they were marking in that situation. The next match someone would not be marking their man and we would concede from a corner in the same silly way. It was very frustrating." (quoted in Bridgewater forthcoming).

In addition to affecting the average quality of play, the manager's playing ability may have differing effects on team success depending on the innate abilities of the players. For example, more highly skilled players may have less to learn than less skilled players. Therefore, a manager who was a great player may disproportionately raise the output of lesser skilled players by teaching them. Of course, as in the case of the manager just quoted, in order to teach players to improve, one needs to get through to them. An additional skill good managers must have is the ability to manage the egos of the team members, particularly if the players themselves are highly skilled. This aspect of managerial skill interacts positively with the players' ability. 
In the current context, there are a number of examples of great football players who were not great football managers. Famously, World Cup Winner, Sir Bobby Charlton spent a brief period as manager of Preston North End before deciding management was not for him, Maradona has had a mixed record with the Argentinian national team and England international, and John Barnes was dismissed after eleven games in charge at Tranmere Rovers in the English League 1. Conversely, top players such as Kenny Dalglish, Mark Hughes, Stuart Pearce and Paul Ince have been both great players and great managers. There are also great managers, such as Sir Alex Ferguson, Jose Mourinho, Arsene Wenger and Sven Goran Eriksson who never played at a high level themselves. Thus, anecdotal evidence in this instance is apparently inconclusive.

Our study will use statistical methods to make general conclusions about the impact of managerial playing ability on English soccer outcomes. We draw on previous econometric research on managerial productivity in sports. Early studies in this area documented the existence of managers' fixed effects in influencing team success. For example, Porter and Scully (1982) used frontier production function analysis to document and measure the extent of managerial inefficiency in Major League Baseball. As discussed further below, this framework assumes that there is a maximum level of output (measured in this instance by team victories) a team could achieve given its inputs. More efficient managers lead to output levels that are closer to this maximum (the frontier of the production set). The authors found considerable variation in the efficiency of baseball managers. Since Porter and Scully's (1982) study, many authors have estimated similar effects in other sports, including Kahane (2005) for the National Hockey League (NHL), Hofler and Payne (2006) for the National Basketball Association (NBA), and most relevant to the current study, Dawson, Dobson and Gerrard (2000a and b), Dawson and Dobson (2002), and Frick and Simmons (2008) for European football. 
While establishing the existence of managerial differences in productive efficiency is an important goal, several studies of productivity in sports go beyond this issue to examine the factors that are related to managers' success. For example, Pfeffer and Davis-Blake (1986) find that an NBA new head coach's past record of success is positively related to current team success. In addition, Kahn (1993) found that among Major League Baseball managers, those with higher predicted salaries (with the predictions based on past record and experience) had higher winning percentages (relative to the team's previous winning percentage) and improved players' performance (relative to the players' previous performance levels) by more than managers with lower predicted salaries. Similarly, Hofler and Payne (2006) found that NBA coaches with more experience, higher career winning percentages, and more current tenure are more productively efficient than otherwise. And Kahane (2005) found that NHL head coaches with higher career winning percentages or those who played for their current team were able to bring the team closer to the production function frontier than otherwise. On the other hand, total coaching experience or total playing experience had no apparent effects on efficiency. Moreover, Goodall, Kahn and Oswald (2008) found that in the NBA, coaches who were themselves former all-star players had significantly better regular season and post-season success than coaches who never played in the NBA or who played but were not all-stars. The authors suggested that managerial expertise as a player led to better performance by current players. ${ }^{1}$

Since the current study concerns British football, we now discuss several studies of European football, and in all cases except one, these studies examined British football. For example, Dawson, Dobson and Gerrard (2000a and b) study various aspects of managerial efficiency in British football over the 1992-98 period, using frontier

\footnotetext{
${ }^{1}$ In another context, Goodall (2009a and b) has found that the publication record of university presidents makes them more successful leaders of research universities, providing further evidence that experts make better leaders than nonexperts.
} 
production function analysis. The authors consider several different issues in estimating productive efficiency, including the measurement of player talent, using fixed effects methods, and whether managerial efficiency is time-varying or invariant. Regarding the measurement of player talent, the authors recommend using ex ante measures. Moreover, Dawson and Dobson (2002) study British football from 1992 to 1998 and find that having played internationally or having previously played or coached for the current team significantly raises a manager's productive efficiency. In addition, the authors find that former forwards make more technically efficient managers. Finally, a recent study of German soccer examines several factors that affect the degree to which managers bring the team closer to productive efficiency (Frick and Simmons 2008). Specifically, head coaches who earn more money and who have better career coaching records lead to significantly more productive efficiency than otherwise.

Our study builds on this previous research in the following ways. First, and most importantly, unlike previous literature, we estimate the degree of substitutability between managerial skill and playing skill in the production process. As discussed in the introduction, substitution/complementarity relationships are fundamental in helping one understand the determinants of relative factor prices as well as from the point of view of managing human resources. Like Dawson and Dobson (2002), Kahane (2005), Hofler and Payne (2006) and Goodall, Kahn and Oswald (2008), we study different aspects of coaching skill, including playing ability as well as coaching knowledge, as proxied by experience. Second, unlike previous work, we pay some attention to the issue of missing data by estimating in some cases models which use multiple imputation techniques for estimating values of missing data. This procedure contrasts with the more familiar design of omitting observations with missing data, and we discuss this issue further below. Third, unlike previous research on European football, we provide separate analyses of leagues below the Premier League in addition to the top league itself. Because the level 
of play is lower in the lesser leagues, it is potentially useful to compare results across leagues, since the large variation in playing ability across leagues allows for a fuller examination of the production function than merely concentrating on top level performers. And production relationships may differ depending on the level of play, implying that one shouldn't pool leagues in estimating production functions and efficiency.

\section{The Setting: English Football}

Competition in English football (soccer) is split into four leagues. ${ }^{2}$ These are open leagues in that teams can be promoted to the level above or relegated to the level below on the basis of performance over the season. The highest of these leagues, the Premier League, now contains twenty clubs (although in 1992-93 and 1993-94, the first years of its formation, the Premier league contained 22 teams). Among the remaining leagues levels $2-4$ are known jointly as the Football League. The highest of these, the second league in England, is known as the Championship, the third league is called League 1, and the fourth League 2. Each of these last three contains 24 (although the Championship also contained 22 clubs in 1992-93 and 1993-94 and changed to 24 clubs when the Premier league changed at the beginning of the 1994-95 season.) There are a total of 92 Clubs in the English Professional Football Leagues. Given the changes in name over time, the leagues are not referred to by name but as "Levels 1 to 4 " in this paper. Performance data are split by league - as a high performance is league 4 is relative to lesser teams than a high performance in league 1. Football seasons run from August of one year until early May of the following year. Each club plays every other club twice in the league - once at home and once at the opponents ground.

\footnotetext{
${ }^{2}$ For further description of English Football, see Bridgewater (forthcoming).
} 


\section{Data and Empirical Procedures}

The data used in this paper are the official statistics on football manager appointments and dismissals and key trends collected by Warwick Business School on behalf of the League Managers Association (LMA) - the football managers' union. Data from the LMA are supplemented by published statistics on performance from two websites: www.soccerbase.com, for football manager data, such as clubs for which the manager played and management experience, and www.footymad.net for league tables and performance data. Data have been collected for the period from the beginning of the 1992-93 English football season through to February 2009, although as explained below, we are only able to use at most the 1994-2007 seasons, due to data availability.

Our aim is to determine whether expert leaders raise the productivity of highly productive workers by more than for less productive workers. In other words, is managers' expertise a substitute for or complement with production workers' expertise? Like several recent papers on the efficiency of management in sports discussed earlier, we take a structural approach which recognizes that the players are the direct input to team success, but where the manager can move the organization toward productive efficiency, when the team achieves its potential output. As discussed, such a design has been termed a frontier production function analysis, and we seek to determine whether expert leaders have larger effects in reducing inefficiency for less productive than for more productive workers. ${ }^{3}$

The data points are each a manager-team-season observation. We use as dependent variable the log of the team's finishing position minus the log of the average team's finishing position for that season, where a larger value means better performance. For

\footnotetext{
${ }^{3}$ For the development of frontier production analysis, see Aigner, Lovell and Schmidt (1977).
} 
example, in a 22 team league, the first finisher gets a 22 and the worst team gets a 1 . We then take the logs of these values and subtract the mean of the log of the finishing positions for the given league and year. We define the manager's playing expertise in a series of dummy variables with four categories:

1. Those who played internationally and in their top domestic league. The requirement to have been both an international player and to have played in the top domestic league is decided upon because some smaller international teams may take players who are the best of that nationality but are not playing at the highest level. So, for example, Wales and Northern Ireland (and Scotland) have international players who are playing in the second tier of the English game.

\section{Those who played in their top domestic league but not internationally.}

These last groups of international but not highest league players are also put into this category on the basis of their international caps, even if their league careers would not have put them into this group.

\section{Those who played in leagues below the top level in their country}

Any manager who played professionally but not in the highest league.

\section{Those who did not play professionally}

Whilst there are not many managers who fall into this category, there are still some. For example, Jose Mourinho is in this category, as was Stuart Murdoch at MK Dons and Lennie Lawrence at the various clubs he has managed.

An additional measure of managerial quality is the amount of managerial experience. This is the case since there is learning by doing and also because the better managers are asked back for future contracts. In either instance, managerial experience is likely to be positively correlated with managerial quality. Since actual performance may affect teams' decisions to employ managers in future years, experience may be endogenous, and we therefore report some results which do not control for experience. We measure managerial playing ability and experience relative to the league average for 
the given season, since the dependent variable is also a relative measure for a given season.

We note that several studies of managerial efficiency in sports control for whether the manager previously played for the current team and also current tenure. We do not control for such factors, since they are likely to be endogenous with respect to current performance. For example, teams are likely to keep their successful managers (raising current tenure), especially if they previously played for the team (producing a positive correlation between having played for the team and winning as a manager). By excluding such variables, we in effect estimate a reduced form.

The players' skills are proxied by the log of the team's real payroll for players minus the log of the average team's payroll for the given league and season. We recognize that this measure is an ex ante indicator of playing skill, although it does have the advantage of placing the manager's abilities into a proper context. Specifically, we are interested in comparing the performance of different types of managers when given teams with the same market value of players. As long as the salaries of the players are positively affected by their skill, a reasonable assumption, this variable will be a measure of that skill; however, like any other measure, including transfer values and even past performance levels, payroll may measure skills with error. ${ }^{4}$ Our maintained hypothesis is that better quality players earn higher salaries, which can then be used as an indicator of playing skill. Szymanski (2003) provides evidence for all major team sports in North America as well as European football that team relative payroll is positively correlated with team success. ${ }^{5}$ Note that we use team payroll rather than more direct measures of

\footnotetext{
${ }^{4}$ For example, Dawson, Dobson and Gerrard (2000a and b) use transfer values as an indicator of playing skill.

5 See Szymanski (2000) and Hall, Szymanski and Zimbalist (2002) for further evidence finding a positive correlation between team payroll and performance in sports. There is some question in the literature as to whether causality runs from payroll to team success or vice-versa. Hall, Szymanski and Zimbalist (2002) address this issue by performing Granger causality tests for baseball and English soccer. The authors in fact find (positive) causality from payroll to performance for soccer for 1974-1999 and for baseball from 1995 to 2000, supporting our use of team payroll as an indicator of playing skill.
} 
player performance. We follow this procedure because these performance measures are potentially affected by the manager, through teaching as well as motivating player performance, and through the manager's substitution patterns, which influence players' opportunities to accumulate playing statistics. In fact, as suggested earlier, more successful managers may make better recruiting decisions, given the level of team payroll, providing an additional avenue through which managerial skill can help teams reach their potential output.

To study the issues of complementarity and substitution, we estimate the following frontier production function model of the determinants of the log of the team's finishing position relative to the average for year $\mathrm{t}$ and team $\mathrm{i}$ :

1) $\ln \left(\right.$ place $\left._{i t}\right)-$ league average $(\ln (\text { place }))_{t}=a_{0}+a_{1}$ relpay $_{i t}+\left(e_{i t}-v_{i t}\right)$,

2) $v_{i t}=f\left(\right.$ experience $_{i t}, D_{i t}$, relpay $_{i t}$, relpay $_{i t}{ }^{*} D_{i t}$, relpay $_{i t}{ }^{*}$ experience $_{i t}$, experience $\left.{ }_{i t}{ }^{*} D_{i t}\right)$

3) $0<=v_{\text {it }}$,

where place is the team's place in the standings in increasing order of success, relpay is the log of the team's payroll for players minus the average log team payroll, experience is the manager's number of years of professional managing experience minus the league average for that year, D is a vector of three dummies summarizing the manager's level of playing minus the league average for that year, with international level (i.e. the top level) as the excluded category. Because the dependent variable is defined relative to other teams in the same league and year, we also define all explanatory variables in the same way. The interaction terms will shed light on the kind of substitution and complementarity relationships we observe among managerial expertise, managerial experience, and players' expertise.

Equation 1) is a structural production function with the players' talent as input. The disturbance consists of two components: e, which is the usual error summarizing 
measurement errors for example, and $\mathrm{v}$, which is a measure of productive inefficiency and is constrained to be nonnegative. Equation 2) expresses the idea that this relative inefficiency is potentially a function of manager characteristics and player skills. Since the dependent variable is a positive indicator of output and since the error component $\mathrm{v}$ enters into the model with a minus sign, a negative interaction effect in equation 2) means a more positive effect on productive efficiency.

Equations 1) and 2) were estimated separately by the four leagues in British football. Because of the problems of repeat observations on individual managers, we estimated the standard errors by bootstrapping, using 20 replications. ${ }^{6}$ We had mostly complete payroll data for 1994-2007 for the top two leagues and 1994-2001 for the two lower level leagues. ${ }^{7}$ Thus, these are the years for which we estimate these models, and we now turn to a description of the results.

\section{Results}

Table 1 shows mean values for selected variables by league. There is a clear sorting of higher playing ability among managers, higher payroll for current players, and a larger amount of managerial experience leading a team into the more elite leagues. Specifically, the incidence of playing at level 1 (i.e. the top level), the number of years of managerial experience, and the average team payroll for players all decline

\footnotetext{
${ }^{6}$ The presence of repeat observations raises the possibility that one could control for manager fixed effects by estimating the within-manager effects of the interaction between payroll and manager's playing ability as well as experience interactions with playing ability and payroll. While we attempted such a model and largely obtained qualitatively similar results to those present below, the results were imprecise, perhaps because in each league, there were only 40-95 individual managers who had multiple years of data. In contrast, there were, overall, 84-143 managers in the total samples within each league. Note that even though the manager's level of play remains constant across observations for the same manager, its interactions with payroll and experience can change, allowing for the estimation of within-manager effects.

${ }^{7}$ Our basic models are estimated deleting any observations with missing data during these sample periods. However, as discussed below, we also estimate some models where we keep the missing data and assign values for payroll using multiple imputation techniques.
} 
monotonically as the level of the current league declines. Moreover, each successive decline across consecutive league types in the incidence of the manager's having played at level 1, years of managerial experience, or team payroll is statistically significant. ${ }^{8}$ In the current Premier League, fully 52\% of the managers played internationally and in their country's top league, while only $14 \%$ of the managers at level 4 did so; managers at level 1 have about 9.3 years' of managerial experience, while those at level 4 have only been managing for 6.5 years; and payrolls for level 1 teams are about 20 times those at level 4 in real terms. ${ }^{9}$ Finally, as discussed above, the leagues are about the same size, making the dependent variable comparable across leagues.

Tables 2-5 show frontier production function results for equations 1) and 2). Looking first at the Premier League, the first model in Table 2 only allows the manager's level of play to affect productive inefficiency. In this model, the effect of player payroll on output is a highly significant 0.447 . Since both the dependent variable and the payroll variable are in logs, this corresponds to an elasticity. An alternative view of the size of this effect is to ask what moving from the $25^{\text {th }}$ to the $75^{\text {th }}$ percentile of the distribution of average team salaries would entail. Using 2000 figures for the 75-25 salary gap for the Premier League (0.697 log points) and a mean finishing position of about 10 and the 0.447 salary coefficient in the first model in Table 2 , we find that moving from the $25^{\text {th }}$ to the $75^{\text {th }}$ payroll level improves the team's position at the mean of standings by about 3.7 places. This is a noticeable effect in a 22 team league. The effects of managerial expertise are insignificant in this specification, which of course constrains their effect to be the same at all payroll and managerial experience levels. ${ }^{10}$ The next specification adds

\footnotetext{
${ }^{8}$ This conclusion is based on ordinary least squares (OLS) regressions of the indicated characteristic on dummy variables for current league level, where the standard errors have been clustered at the manager level.

9 The 20:1 payroll ratio is based on the raw means for real payroll.

${ }^{10}$ This insignificance contrasts with the results of Dawson and Dobson (2002) who found that having played at an international level was associated with more managerial efficiency. Their finding was based on a model which pooled various levels of English football. When we pooled the four leagues, we indeed found that having played at level 2 led to significantly less efficiency than having played at level 1, a
} 
managerial experience to the factors that potentially influence productive inefficiency; while the coefficient on experience has the expected negative sign (i.e., managerial experience on average lowers productive inefficiency), it is not significant.

While the first two specifications for the productive inefficiency do not show significant main effects for managerial expertise or experience, the third specification shows that player skill significantly interacts with the manager's expertise in bringing the team closer to its productive potential. Specifically, in affecting productive inefficiency, player payroll has negative interaction effects with the manager's playing ability at levels 2,3 , and 4 , all relative to managers who played at the top level (the log relative payroll main inefficiency effect). Moreover, the interactions are monotonically increasing in absolute value, ranging from -0.308 for level 2 to -2.412 for managers who didn't play. And the interactions for levels 3 and 4 are significant at the $0.8 \%$ and $3.6 \%$ levels respectively, on two tailed tests. The interaction effect for managers who didn't play is large in magnitude. For example, the impact of a 75-25 increase in player pay lowers productive inefficiency by $1.67 \log$ points more for a manager who didn't play versus a manager who played at level 1 , or by about 81 percentage points. ${ }^{11}$

The main effect of log payroll in the analysis of productive inefficiency is the impact of payroll for teams managed by former top level players. It also is significantly negative; in conjunction with the negative interactions for each of the lesser playing ability types of managers, we find evidence that in addition to directly affecting potential output, better paid players enable teams to achieve results closer to their potential. Of

similar result to Dawson and Dobson (2002). However, the findings shown below suggest that it is inappropriate to pool the different leagues. In addition, when we added a dummy variable for whether the manager played for the current team, we found a significantly positive effect on efficiency, as Dawson and Dobson (2002) did, while the other results were unchanged. However, as argued above, we believe that this variable is endogenous and should not be included.

11 These large predicted increases in efficiency must of course be interpret cautiously, in light of the fact that the mean efficiency was about .5 for each league. Nonetheless the large implied effects of these substantial payroll changes do suggest that a higher payroll raises the productive efficiency of less expert (with respect to playing ability) managers by substantially more than for more expert managers. 
course this division of the impact of player skills into direct effects on potential output and indirect effects through their impact on productive efficiency is dependent on the production function model being correct. However, the result does shed light on the routes through which worker and manager skills lead to organizational success.

The fourth specification in Table 2 adds an interaction between player payroll and the manager's experience. This effect is negative and significant at the $2.8 \%$ level. A 75-25 change in the manager's experience is roughly 9 years (i.e. 13 vs. 4 years' managing experience), implying that the interaction coefficient of -0.100 represents a large effect indeed. Adding the experience-payroll interaction effect does, however, reduce the size of the payroll-manager's playing ability interactions by about a third for levels 3 and 4 and by $81 \%$ for level 2 . The payroll-manager's playing ability interactions still increase monotonically in magnitude as the manager's playing ability decreases from level 1 to level 4, and remain statistically significant for levels 3 and 4 (at the $2.9 \%$ and $4.6 \%$ levels respectively). Finally, there do not seem to be any important managerial experience-managerial playing ability interaction effects, although adding these variables raises the standard errors on the payroll-manager's playing ability interactions without affecting their magnitude. ${ }^{12}$

The basic results for the Premier League, then, suggest the following conclusions. First, teams really do receive something in return for a higher payroll, both directly on potential output and indirectly by having a more technically efficient team (i.e., one which achieves at a level closer to its potential). Second, managerial playing skill raises productive efficiency by more for teams with lower quality than higher quality players. And, third, managerial experience raises productive efficiency by more for more highly skilled players. These disparate interaction effects suggest that there are multiple

\footnotetext{
12 The three experience-managerial playing ability interactions were insignificant as a group as well as individually.
} 
dimensions of managerial skill. On the one hand, the interactions for managerial playing quality and team payroll for players suggest that leaders who are experts at the sport have more to teach lesser skilled than more skilled players. The more highly skilled players, as indicated by a higher payroll, benefit less from a manager who was a great player, since these players already know how to play well. On the other hand, the effects of managerial experience suggest that long time managers know how to manage the egos of star players. More experienced managers bring more highly skilled players closer to their potential than when they manage less highly skilled players. Either such knowledge was obtained through on the job learning or managers who are better at managing big egos are selected by the Premier League teams to have long careers.

Tables 3-5 show results for the lower level leagues and are in general weaker than for the Premier League. In each of levels 2-4, the direct effect of player payroll on team potential success is positive and is usually significant: better-paid players are associated with a higher level of potential output at each league level. This positive effect of player payroll serves as some validation of payroll as a positive indicator of player skill. The production function parameter for team payroll for the Premier League is larger than for levels 2 and 3 and about the same size as the effect for level 4. Thus the elasticity of output with respect to player ability is at least as large for the Premier League as for the other leagues. Moreover, since the 75-25 gaps for the 2000 season for levels 2-4 are, respectively, 0.700, 0.663, and 0.568, compared to the Premier League's value of 0.697, an increase in payroll of this magnitude would also have effects at least as large for the Premier League as for the other leagues. In addition to positively affecting potential output, player payroll also appears to raise productive efficiency in levels 2-4, as it did for the Premier League, with several of the effects being statistically significant and large in magnitude. Moreover, at level 3, there is large main effect of managerial experience on efficiency that is statistically significant. Specifically, the second model in Table 4 
shows a coefficient on managerial experience of -0.227 with a standard error of 0.109 . For the year 2000, the 75-25 gap in experience for level 3 is 5.5 years (i.e. 6.5 vs. 1), implying that an increase of this magnitude in experience lowers inefficiency by about $1.1 \log$ points, or 67 percentage points. Finally, again for level 3, Table 4 shows that player payroll has a significantly larger effect in lowering inefficiency for managers who played at level 2 vs. level 1. The direction of this effect is similar to the impact in the Premier League, although for the level 3 league, the interactions do not rise monotonically as the manager's playing skill declines. ${ }^{13}$

The finding of stronger payroll-manager playing skill and managerial experiencepayroll interactions for the Premier League than for the other leagues deserves further comment. Specifically, we have interpreted the positive manager experience-payroll effects in the Premier League as reflecting an experienced manager's ability to manage the egos of highly paid players. It is intuitive that such egos will be more on display at the top levels of the Premier League than in the lower leagues, making it plausible that we would observe this effect to a greater degree at the top level of play. On the other hand, the negative interactions between managerial playing ability and player payroll suggest, we have argued, that managers who were great players have more to teach lesser players than more accomplished current players. One might have expected such effects to be stronger in the lesser leagues, where the players presumably have more to learn than in the Premier League. Perhaps the answer is in the nature of the instruction that a manager who was a top level player provides to lesser players in the Premier League relative to lesser players in the lower level leagues. In the Premier League, players compete for higher stakes than in the other leagues, and lesser players in the top league

\footnotetext{
13 As suggested by Dawson, Dobson and Gerrard (2000b), managerial efficiency may not be constant over time. When we reestimated our models adding a time trend for the determination of inefficiency, the results in every case were small and statistically insignificant. In addition, when we included a dummy variable for having played forward professionally, its effects were insignificant, unlike Dawson and Dobson (2002).
} 
may have more to learn about how to compete in such an environment than in the lower leagues.

As noted earlier, in some cases, there were missing data for player payroll, amounting to 6 cases for the Premier League (2\% of the observations), 40 cases for level $2(9 \%), 27$ cases for level $3(11 \%)$, and 71 cases for level $4(30 \%)$. In addition, there was one missing case for the manager's experience level for the Premier League. In Appendix Tables A1-A4, we show frontier production function results where we employ multiple imputation techniques suggested by Rubin (1987) to use the observed data on the explanatory variables to impute values for the missing data. In some instances, this can be a superior procedure to merely omitting cases with missing data; for example, if there is a systematic relationship between the observed explanatory variables and the incidence of missing cases, then omitting the missing cases may lead to a selected, nonrepresentative sample. This outcome would not cause problems if the effects of the key explanatory variables were the same for everyone. However, in the likely event that individuals have their own specific effects of particular right hand variables, then models such as ours will in effect be estimating average treatment effects across individuals with potentially heterogeneous treatment effects. Using an unrepresentative sample, therefore, may not produce the average treatment effect for the entire population. Of course, multiple imputations do not correct for this problem if there are important unmeasured factors distinguishing the cases with missing data from those with complete data. In any event, the results in Tables A1)-A4) are quite similar in magnitude to those in Tables 2-5, although they are less statistically significant. Thus, our basic findings do not appear to be an artifact of the sample with complete data.

\section{Conclusions}


In this paper, we have used data on British football managers over the 1994-2007 period to study the issue of substitution and complementarity between leaders and subordinates. This setting is a particularly fruitful one for examining such production relationships because we have clear data on each organization's performance (i.e., its finishing position during the current season) and the type of both production and managerial labor inputs used.

Our strongest results are for the Premier League (the highest level of competition) and show that, other things being equal, managers who played at a higher level raise the productivity of lesser skilled teams by more than they do of more highly skilled teams. This finding is consistent with the hypothesis that one of the functions of a highly skilled manager is to teach subordinates some of the skills needed to succeed. The value of this teaching is, according to our results, greater the less skilled the players are. Such a result, which we believe is a new one, seems intuitively plausible. An additional finding, however, suggests that other things being equal (including the manager's playing ability), managers with more accumulated professional managing experience raise the productivity of more skilled players by more than that of less skilled players. This finding is consistent with the idea that another role of successful managers in highpressure, high-performance workplaces may be to manage the egos of the workers involved. Such a role is likely to be more critical the more accomplished the workers are, as indicated in our data by teams with higher relative payroll levels. 


\section{References}

Aigner, Dennis, Lovell, C. A. Knox, Schmidt, Peter. 1977. Formulation and estimation of stochastic frontier production function models. Journal of Econometrics 6, 2137 no. 1 (July).

Bridgewater, Sue. Forthcoming. Football Management. Basingstoke and New York: Palgrave Macmillan.

Dawson, Peter, Dobson, Stephen. 2002. Managerial efficiency and human capital: an application to English Association football. Managerial and Decision Economics 23, 471-486 no. 8 (December).

Dawson, Peter, Dobson, Stephen, Gerrard, Bill. 2000a. Estimating coaching efficiency in professional team sports: evidence from English Association football. Scottish Journal of Political Economy 47, 399-421 no. 4 (September).

Dawson, Peter, Dobson, Stephen, Gerrard, Bill. 2000b. Stochastic frontiers and the temporal structure of managerial efficiency in English soccer. Journal of Sports Economics 1, 341-362 no. 4 (November).

Frick, Bernd, Simmons, Robert. 2008. The impact of managerial quality on organizational performance: evidence from German soccer. Managerial and Decision Economics 29, 593-600 no. 7 (October).

Goodall, Amanda H. 2009a. Highly cited leaders and the performance of research universities. Research Policy 38, (7): 1079-1092 (September).

Goodall, Amanda H. 2009b. Socrates in the Boardroom: Why Research Universities Should be Led by Top Scholars. Princeton University Press: Princeton and Oxford (October).

Goodall, Amanda H., Kahn, Lawrence M., Oswald, Andrew J. 2008. Why do leaders matter? The role of expert knowledge in a high-skill setting. IZA Discussion Paper No. 3583 and working paper, Cornell University, (May).

Hall, Stephen, Szymanski, Stefan, Zimbalist, Andrew S. 2002. Testing causality between team performance and payroll. Journal of Sports Economics 3, 149-168 no. 2 (May).

Hofler, Richard A, Payne, James E. 2006. Efficiency in the National Basketball Association: a stochastic frontier approach with panel data. Managerial and Decision Economics 27, 279-285 no.4 (June).

Kahane, Leo H. 2005. Production efficiency and discriminatory hiring practices in the National Hockey League: a stochastic frontier approach. Review of Industrial Organization 27, 47-71 no. 1 (August).

Kahn, Lawrence M. 1993. Managerial quality, team success and individual player performance in Major League Baseball. Industrial \& Labor Relations Review 46, 531-547 no. 3 (April). 
Pfeffer, Jeffrey, Davis-Blake, Alison. 1986. Administrative succession and organizational performance: how administrator experience mediates the succession effect. Academy of Management Journal 29, 72-83 no. 1 (March).

Porter, Philip K., Scully, Gerald W. 1982. Measuring managerial efficiency: the case of baseball. Southern Economic Journal 48, 642-650 no. 3 (January).

Rubin, Donald B. 1987. Multiple Imputation for Nonresponse in Surveys. New York: Wiley.

Szymanski, Stefan. 2000. A market test for discrimination in the English professional soccer leagues. Journal of Political Economy 108, 590-603 no. 3 (June).

Szymanski, Stefan. 2003. The economic design of sporting contests. Journal of Economic Literature 41, 1137-1187 no. 4 (December). 
Table 1: Managers' Mean Values by League

\section{League}

$\begin{array}{lcccc}\text { Variable } & \text { Level 1 } & \text { Level 2 } & \text { Level 3 } & \text { Level 4 } \\ \text { Manager Played at Level 1 } & 0.523 & 0.383 & 0.256 & 0.143 \\ \text { Manager Played at Level 2 } & 0.078 & 0.170 & 0.177 & 0.220 \\ \text { Manager Played at Level 3 } & 0.351 & 0.370 & 0.484 & 0.500 \\ \text { Manager Never Played } & 0.048 & 0.078 & 0.084 & 0.137 \\ \text { Manager's Experience (years) } & 9.413 & 6.851 & 4.468 & 3.141 \\ \text { Log Team Real Payroll for Players } & 9.292 & 8.100 & 7.022 & 6.494 \\ & & & & \\ \text { Sample Size } & 333 & 400 & 215 & 168\end{array}$


Table 2: Frontier Production Function Analysis for Relative League Position, Premier League Teams

\begin{tabular}{|c|c|c|c|c|c|c|c|c|c|c|}
\hline & coef & se & coef & se & coef & se & coef & se & coef & se \\
\hline \multicolumn{11}{|l|}{ Production Function Parameter: } \\
\hline Log Team Relative Payroll & 0.447 & 0.188 & 0.440 & 0.087 & 0.223 & 0.067 & 0.218 & 0.064 & 0.217 & 0.055 \\
\hline \multicolumn{11}{|l|}{ Technical Inefficiency Parameters: } \\
\hline & coef & se & coef & se & coef & se & coef & se & coef & se \\
\hline Manager Played at Level 2 & 2.110 & 1.777 & 2.120 & 1.708 & 0.391 & 0.394 & 0.446 & 0.561 & 0.412 & 0.567 \\
\hline Manager Played at Level 3 & -0.551 & 1.069 & -0.271 & 3.256 & -0.358 & 0.362 & -0.283 & 0.333 & -0.085 & 0.366 \\
\hline Manager Did Not Play & 0.476 & 2.210 & 0.819 & 2.604 & 0.462 & 0.523 & 0.623 & 0.709 & 0.661 & 2.355 \\
\hline Manager's Experience & & & -0.071 & 0.085 & 0.008 & 0.013 & -0.015 & 0.023 & -0.007 & 0.029 \\
\hline Log Relative Payroll & & & & & -2.279 & 0.258 & -1.615 & 0.567 & -1.598 & 0.594 \\
\hline Log Relative Payroll*Played Level 2 & & & & & -0.308 & 0.877 & -0.058 & 1.492 & -0.102 & 0.981 \\
\hline Log Relative Payroll*Played Level 3 & & & & & -1.308 & 0.495 & -0.891 & 0.408 & -0.829 & 0.902 \\
\hline Log Relative Payroll*Never Played & & & & & -2.414 & 1.153 & -1.659 & 0.830 & -1.585 & 1.050 \\
\hline \multicolumn{11}{|l|}{ Manager's Experience*Log Team } \\
\hline Relative Payroll & & & & & & & -0.100 & 0.045 & -0.107 & 0.046 \\
\hline Manager's Experience*Played Level 2 & & & & & & & & & 0.001 & 0.063 \\
\hline Manager's Experience*Played Level 3 & & & & & & & & & -0.020 & 0.023 \\
\hline Manager's Experience*Never Played & & & & & & & & & -0.006 & 0.214 \\
\hline Sample size & 333 & & 333 & & 333 & & 333 & & 333 & \\
\hline
\end{tabular}

Relative position is defined as the difference between the log of team's finishing position and the average of the logs of the finishing positions of the teams in each given year. Finishing position is defined in direct order of success (i.e. a higher value means a better finish). Therefore a negative coefficient in the technical inefficiency analysis actually represents more technical efficiency. Explanatory variables are each defined relative to the league average for each year. Standard errors are bootstrapped using 20 replications. 
Table 3: Frontier Production Function Analysis for Relative League Position, Level Two League Teams

\begin{tabular}{|c|c|c|c|c|c|c|c|c|c|c|}
\hline & coef & se & coef & se & coef & se & coef & se & coef & se \\
\hline \multicolumn{11}{|l|}{ Production Function Parameter: } \\
\hline Log Team Relative Payroll & 0.320 & 0.079 & 0.308 & 0.086 & 0.134 & 0.071 & 0.133 & 0.062 & 0.133 & 0.037 \\
\hline \multicolumn{11}{|l|}{ Technical Inefficiency Parameters: } \\
\hline & coef & se & coef & se & coef & se & coef & se & coef & se \\
\hline Manager Played at Level 2 & 0.080 & 0.806 & 0.036 & 0.825 & -0.173 & 0.454 & -0.173 & 0.475 & -0.162 & 0.687 \\
\hline Manager Played at Level 3 & 0.371 & 0.641 & 0.447 & 0.677 & 0.003 & 0.397 & 0.003 & 0.416 & 0.282 & 0.597 \\
\hline Manager Did Not Play & 0.688 & 1.202 & 0.992 & 1.291 & 0.102 & 0.969 & 0.102 & 0.876 & 0.458 & 1.113 \\
\hline Manager's Experience & & & -0.071 & 0.066 & -0.025 & 0.031 & -0.025 & 0.030 & 0.002 & 0.048 \\
\hline Log Relative Payroll & & & & & -2.428 & 0.412 & -2.425 & 0.874 & -2.445 & 0.646 \\
\hline Log Relative Payroll*Played Level 2 & & & & & -0.498 & 0.761 & -0.498 & 0.807 & -0.400 & 0.944 \\
\hline Log Relative Payroll*Played Level 3 & & & & & 0.906 & 0.751 & 0.907 & 0.639 & 1.039 & 0.707 \\
\hline Log Relative Payroll*Never Played & & & & & 1.088 & 1.143 & 1.092 & 1.072 & 1.164 & 0.942 \\
\hline \multicolumn{11}{|l|}{ Manager's Experience*Log Team } \\
\hline Relative Payroll & & & & & & & -0.001 & 0.061 & -0.007 & 0.043 \\
\hline Manager's Experience*Played Level 2 & & & & & & & & & -0.002 & 0.087 \\
\hline Manager's Experience*Played Level 3 & & & & & & & & & -0.043 & 0.070 \\
\hline Manager's Experience*Never Played & & & & & & & & & -0.049 & 0.084 \\
\hline Sample size & 400 & & 400 & & 400 & & 400 & & 400 & \\
\hline
\end{tabular}

Relative position is defined as the difference between the log of team's finishing position and the average of the logs of the finishing positions of the teams in each given year. Finishing position is defined in direct order of success (i.e. a higher value means a better finish). Therefore a negative coefficient in the technical inefficiency analysis actually represents more technical efficiency. Explanatory variables are each defined relative to the league average for each year. Standard errors are bootstrapped using 20 replications. 
Table 4: Frontier Production Function Analysis for Relative League Position, Level Three League Teams

Production Function Parameter:

\begin{tabular}{|c|c|c|c|c|c|c|c|c|c|}
\hline coef & se & coef & se & coef & se & coef & se & coef & se \\
\hline 0.254 & 0.222 & 0.251 & 0.074 & 0.101 & 0.063 & 0.106 & 0.074 & 0.113 & 0.082 \\
\hline coef & se & coef & se & coef & se & coef & se & coef & se \\
\hline 1.237 & 1.153 & 0.752 & 0.512 & -0.095 & 0.470 & -0.068 & 0.413 & -0.844 & 0.633 \\
\hline-0.598 & 1.007 & -0.607 & 0.682 & -0.593 & 0.313 & -0.582 & 0.395 & -1.150 & 0.411 \\
\hline \multirow[t]{10}{*}{0.562} & 1.146 & 0.403 & 0.719 & -0.289 & 0.796 & -0.363 & 0.602 & -1.018 & 0.688 \\
\hline & & -0.227 & 0.109 & -0.125 & 0.045 & -0.115 & 0.047 & -0.248 & 0.100 \\
\hline & & & & -1.358 & 0.914 & -1.973 & 0.609 & -2.100 & 1.642 \\
\hline & & & & -3.604 & 1.501 & -3.254 & 1.170 & -3.025 & 1.397 \\
\hline & & & & -1.013 & 1.150 & -0.636 & 0.749 & -0.537 & 1.244 \\
\hline & & & & -1.547 & 2.063 & -1.378 & 1.532 & -1.581 & 1.740 \\
\hline & & & & & & 0.110 & 0.107 & 0.134 & 0.147 \\
\hline & & & & & & & & 0.227 & 0.142 \\
\hline & & & & & & & & 0.151 & 0.090 \\
\hline & & & & & & & & 0.170 & 0.294 \\
\hline 215 & & 215 & & 215 & & 215 & & 215 & \\
\hline
\end{tabular}

Relative position is defined as the difference between the log of team's finishing position and the average of the logs of the finishing positions of the teams in each given year. Finishing position is defined in direct order of success (i.e. a higher value means a better finish). Therefore a negative coefficient in the technical inefficiency analysis actually represents more technical efficiency. Explanatory variables are each defined relative to the league average for each year. Standard errors are bootstrapped using 20 replications. 
Table 5: Frontier Production Function Analysis for Relative League Position, Level Four League Teams

\begin{tabular}{|c|c|c|c|c|c|c|c|c|c|c|}
\hline & coef & se & coef & se & coef & se & coef & se & coef & se \\
\hline \multicolumn{11}{|l|}{ Production Function Parameter: } \\
\hline Log Team Relative Payroll & 0.469 & 0.134 & 0.446 & 0.143 & 0.367 & 0.123 & 0.362 & 0.159 & 0.364 & 0.194 \\
\hline \multicolumn{11}{|l|}{ Technical Inefficiency Parameters: } \\
\hline & coef & se & coef & se & coef & se & coef & se & coef & se \\
\hline Manager Played at Level 2 & 1.311 & 5.414 & 1.156 & 1.716 & 1.187 & 0.985 & 1.295 & 1.278 & 0.934 & 1.491 \\
\hline Manager Played at Level 3 & 0.447 & 5.041 & 0.438 & 1.441 & 0.597 & 0.801 & 0.714 & 1.558 & -0.792 & 1.603 \\
\hline Manager Did Not Play & 1.198 & 5.080 & 1.025 & 1.236 & 1.048 & 0.633 & 1.111 & 1.409 & 0.322 & 1.935 \\
\hline Manager's Experience & & & -0.139 & 0.131 & -0.108 & 0.099 & -0.082 & 0.105 & -0.403 & 0.308 \\
\hline Log Relative Payroll & & & & & -5.501 & 4.798 & -4.910 & 5.512 & -4.288 & 3.122 \\
\hline Log Relative Payroll*Played Level 2 & & & & & 3.420 & 4.906 & 3.149 & 4.278 & 3.950 & 3.125 \\
\hline Log Relative Payroll*Played Level 3 & & & & & 5.116 & 4.889 & 5.059 & 5.584 & 4.542 & 2.778 \\
\hline Log Relative Payroll*Never Played & & & & & 3.397 & 4.811 & 3.115 & 5.728 & 3.020 & 3.314 \\
\hline \multicolumn{11}{|l|}{ Manager's Experience*Log Team } \\
\hline Relative Payroll & & & & & & & -0.219 & 0.381 & -0.473 & 0.333 \\
\hline Manager's Experience*Played Level 2 & & & & & & & & & 0.041 & 0.331 \\
\hline Manager's Experience*Played Level 3 & & & & & & & & & 0.500 & 0.342 \\
\hline Manager's Experience*Never Played & & & & & & & & & 0.206 & 0.391 \\
\hline Sample size & 168 & & 168 & & 168 & & 168 & & 168 & \\
\hline
\end{tabular}

Relative position is defined as the difference between the log of team's finishing position and the average of the logs of the finishing positions of the teams in each given year. Finishing position is defined in direct order of success (i.e. a higher value means a better finish). Therefore a negative coefficient in the technical inefficiency analysis actually represents more technical efficiency. Explanatory variables are each defined relative to the league average for each year. Standard errors are bootstrapped using 20 replications. 
Table A1: Frontier Production Function Analysis for Relative League Position With Time Trend for Productive Inefficiency and Multiple Imputations for Missing Data, Premier League (Level 1)

\begin{tabular}{|c|c|c|c|c|c|c|}
\hline & coef & se & coef & se & coef & se \\
\hline \multicolumn{7}{|l|}{ Production Function Parameter: Log } \\
\hline Team Relative Payroll & 0.249 & 0.048 & 0.243 & 0.047 & 0.240 & 0.047 \\
\hline Technical Inefficiency Parameters: & coef & se & coef & se & coef & se \\
\hline Manager Played at Level 2 & 0.362 & 0.588 & 0.422 & 0.574 & 0.200 & 0.905 \\
\hline Manager Played at Level 3 & -0.231 & 0.319 & -0.162 & 0.310 & 0.221 & 0.498 \\
\hline Manager Did Not Play & 1.043 & 0.595 & 1.198 & 0.589 & 0.412 & 1.403 \\
\hline Manager's Experience & 0.000 & 0.019 & -0.021 & 0.022 & -0.009 & 0.030 \\
\hline Log Relative Payroll & -2.172 & 0.547 & -1.500 & 0.572 & -1.424 & 0.569 \\
\hline Log Relative Payroll*Played Level 2 & -0.483 & 1.435 & -0.203 & 1.402 & -0.387 & 1.487 \\
\hline Log Relative Payroll*Played Level 3 & -1.300 & 0.691 & -0.846 & 0.690 & -0.719 & 0.685 \\
\hline Log Relative Payroll*Never Played & -1.549 & 1.255 & -0.830 & 1.197 & -0.796 & 1.223 \\
\hline \multicolumn{7}{|l|}{ Manager's Experience*Log Team } \\
\hline Relative Payroll & & & -0.104 & 0.051 & -0.120 & 0.055 \\
\hline Manager's Experience*Played Level 2 & & & & & 0.017 & 0.068 \\
\hline Manager's Experience*Played Level 3 & & & & & -0.039 & 0.042 \\
\hline Manager's Experience*Never Played & & & & & 0.056 & 0.102 \\
\hline Sample size & 339 & & 339 & & 339 & \\
\hline
\end{tabular}

Relative position is defined as the difference between the log of team's finishing position and the average of the logs of the finishing positions of the teams in each given year. Finishing position is defined in direct order of success (i.e. a higher value means a better finish). Therefore a negative coefficient in the technical inefficiency analysis actually represents more technical efficiency. Explanatory variables are each defined relative to the league average for each year. All variables involving pay and experience imputed. 10 imputations are performed, but only 7 could be used in the second stage equations, due to. convergence problems. All non-imputed explanatory variables are used as predictors in the imputations. 
Table A2: Frontier Production Function Analysis for Relative League Position With Time Trend for Productive Inefficiency and Multiple Imputations for Missing Data, Level 2 League

Production Function Parameter: Log Team Relative Payroll

Technical Inefficiency Parameters:

Manager Played at Level 2

Manager Played at Level 3

Manager Did Not Play

Manager's Experience

Log Relative Payroll

Log Relative Payroll*Played Level 2

Log Relative Payroll*Played Level 3

Log Relative Payroll*Never Played

Manager's Experience*Log Team

Relative Payroll

Manager's Experience*Played Level 2 Manager's Experience*Played Level 3 Manager's Experience*Never Played Sample size

\begin{tabular}{|c|c|c|c|c|c|}
\hline coef & se & coef & se & coef & se \\
\hline 0.151 & 0.046 & 0.151 & 0.046 & 0.151 & 0.046 \\
\hline coef & se & coef & se & coef & se \\
\hline-0.235 & 0.424 & -0.233 & 0.425 & -0.286 & 0.655 \\
\hline-0.098 & 0.358 & -0.097 & 0.358 & -0.014 & 0.545 \\
\hline-0.064 & 0.714 & -0.065 & 0.715 & -0.006 & 0.965 \\
\hline-0.049 & 0.029 & -0.049 & 0.030 & -0.043 & 0.052 \\
\hline-2.189 & 0.648 & -2.187 & 0.726 & -2.200 & 0.734 \\
\hline-0.315 & 0.973 & -0.312 & 0.970 & -0.282 & 0.977 \\
\hline 0.960 & 0.868 & 0.962 & 0.871 & 0.998 & 0.901 \\
\hline \multirow[t]{5}{*}{0.826} & 1.135 & 0.826 & 1.212 & 0.833 & 1.228 \\
\hline & & -0.0003 & 0.061 & -0.0004 & 0.064 \\
\hline & & & & 0.010 & 0.096 \\
\hline & & & & -0.013 & 0.067 \\
\hline & & & & -0.010 & 0.087 \\
\hline 440 & & 440 & & 440 & \\
\hline
\end{tabular}

Relative position is defined as the difference between the log of team's finishing position and the average of the logs of the finishing positions of the teams in each given year. Finishing position is defined in direct order of success (i.e. a higher value means a betterfinish). Therefore a negative coefficient in the technical inefficiency analysis actually represents more technical efficiency. Explanatory variables are each defined relative to the league average for each year. All variables involving pay and experience imputed. 10 imputations are performed. All non-imputed explanatory variables are used as predictors in the imputations. 
Table A3: Frontier Production Function Analysis for Relative League Position With Time Trend for Productive Inefficiency and Multiple Imputations for Missing Data, Level 3 League

\begin{tabular}{|c|c|c|c|c|c|c|}
\hline & coef & se & coef & se & coef & se \\
\hline \multicolumn{7}{|l|}{ Production Function Parameter: Log } \\
\hline Team Relative Payroll & 0.023 & 0.065 & 0.026 & 0.067 & 0.028 & 0.068 \\
\hline Technical Inefficiency Parameters: & coef & se & coef & se & coef & se \\
\hline Manager Played at Level 2 & -0.460 & 0.448 & -0.442 & 0.444 & -1.009 & 0.572 \\
\hline Manager Played at Level 3 & -0.892 & 0.393 & -0.887 & 0.387 & -1.136 & 0.517 \\
\hline Manager Did Not Play & -0.223 & 0.575 & -0.294 & 0.581 & -0.699 & 0.857 \\
\hline Manager's Experience & -0.117 & 0.045 & -0.113 & 0.044 & -0.180 & 0.074 \\
\hline Log Relative Payroll & -1.478 & 0.797 & -1.882 & 1.047 & -1.991 & 1.023 \\
\hline Log Relative Payroll*Played Level 2 & -3.107 & 1.473 & -2.870 & 1.504 & -2.571 & 1.458 \\
\hline Log Relative Payroll*Played Level 3 & -0.676 & 1.088 & -0.439 & 1.119 & -0.316 & 1.086 \\
\hline Log Relative Payroll*Never Played & -1.130 & 1.787 & -1.075 & 1.752 & -1.213 & 2.021 \\
\hline \multicolumn{7}{|l|}{ Manager's Experience*Log Team } \\
\hline Relative Payroll & & & 0.065 & 0.112 & 0.081 & 0.117 \\
\hline Manager's Experience*Played Level 2 & & & & & 0.167 & 0.100 \\
\hline Manager's Experience*Played Level 3 & & & & & 0.063 & 0.089 \\
\hline Manager's Experience*Never Played & & & & & 0.092 & 0.131 \\
\hline Sample size & 242 & & 242 & & 242 & \\
\hline
\end{tabular}

Relative position is defined as the difference between the log of team's finishing position and the average of the logs of the finishing positions of the teams in each given year. Finishing position is defined in direct order of success (i.e. a higher value means a better finish). Therefore a negative coefficient in the technical inefficiency analysis actually represents more technical efficiency. Explanatory variables are each defined relative to the league average for each year. All variables involving pay and experience imputed. 10 imputations are performed. All non-imputed explanatory variables are used as predictors in the imputations. 
Table A4: Frontier Production Function Analysis for Relative League Position With Time Trend for Productive Inefficiency and Multiple Imputations for Missing Data, Level 4 League

\begin{tabular}{|c|c|c|c|c|c|c|}
\hline & coef & se & coef & se & coef & se \\
\hline \multicolumn{7}{|l|}{ Production Function Parameter: Log } \\
\hline Team Relative Payroll & 0.110 & 0.059 & 0.110 & 0.059 & 0.110 & 0.059 \\
\hline Technical Inefficiency Parameters: & coef & se & coef & se & coef & se \\
\hline Manager Played at Level 2 & 1.443 & 0.894 & 1.465 & 0.913 & 0.929 & 1.135 \\
\hline Manager Played at Level 3 & 1.009 & 0.788 & 1.024 & 0.816 & 0.326 & 1.018 \\
\hline Manager Did Not Play & 0.448 & 0.988 & 0.469 & 1.000 & -0.316 & 1.479 \\
\hline Manager's Experience & 0.030 & 0.081 & 0.033 & 0.109 & -0.139 & 0.213 \\
\hline Log Relative Payroll & -3.489 & 4.272 & -3.267 & 4.515 & -3.325 & 4.359 \\
\hline Log Relative Payroll*Played Level 2 & 2.393 & 4.800 & 2.243 & 4.974 & 2.535 & 4.827 \\
\hline Log Relative Payroll*Played Level 3 & 2.599 & 4.532 & 2.500 & 4.503 & 2.589 & 4.383 \\
\hline Log Relative Payroll*Never Played & 1.966 & 5.307 & 1.826 & 5.424 & 1.971 & 5.209 \\
\hline \multicolumn{7}{|l|}{ Manager's Experience*Log Team } \\
\hline Relative Payroll & & & -0.043 & 0.403 & -0.095 & 0.426 \\
\hline Manager's Experience*Played Level 2 & & & & & 0.156 & 0.296 \\
\hline Manager's Experience*Played Level 3 & & & & & 0.213 & 0.245 \\
\hline Manager's Experience*Never Played & & & & & 0.259 & 0.433 \\
\hline Sample size & 239 & & 239 & & 239 & \\
\hline
\end{tabular}

Relative position is defined as the difference between the log of team's finishing position and the average of the logs of the finishing positions of the teams in each given year. Finishing position is defined in direct order of success (i.e. a higher value means a better finish). Therefore a negative coefficient in the technical inefficiency analysis actually represents more technical efficiency. Explanatory variables are each defined relative to the league average for each year. All variables involving pay and experience imputed. 5 imputations are performed. All non-imputed explanatory variables are used as predictors in the imputations. 


\section{List of NCER Working Papers}

No. 50 (Download full text)

Martin Fukac and Adrian Pagan

Structural Macro-Econometric Modelling in a Policy Environment

No. 49 (Download full text)

Tim M Christensen, Stan Hurn and Adrian Pagan

Detecting Common Dynamics in Transitory Components

No. 48 (Download full text)

Egon Franck, Erwin Verbeek and Stephan Nüesch

Inter-market Arbitrage in Sports Betting

No. 47 (Download full text)

Raul Caruso

Relational Good at Work! Crime and Sport Participation in Italy. Evidence from Panel Data Regional Analysis over the Period 1997-2003.

No. 46 (Download full text) (Accepted)

Peter Dawson and Stephen Dobson

The Influence of Social Pressure and Nationality on Individual Decisions: Evidence from the Behaviour of Referees

No. 45 (Download full text)

Ralf Becker, Adam Clements and Christopher Coleman-Fenn

Forecast performance of implied volatility and the impact of the volatility risk premium

No. 44 (Download full text)

Adam Clements and Annastiina Silvennoinen

On the economic benefit of utility based estimation of a volatility model

No. 43 (Download full text)

Adam Clements and Ralf Becker

A nonparametric approach to forecasting realized volatility

No. 42 (Download full text)

Uwe Dulleck, Rudolf Kerschbamer and Matthias Sutter

The Economics of Credence Goods: On the Role of Liability, Verifiability, Reputation and

Competition

No. 41 (Download full text)

Adam Clements, Mark Doolan, Stan Hurn and Ralf Becker

On the efficacy of techniques for evaluating multivariate volatility forecasts

No. 40 (Download full text)

Lawrence M. Kahn

The Economics of Discrimination: Evidence from Basketball 
No. 39 (Download full text)

Don Harding and Adrian Pagan

An Econometric Analysis of Some Models for Constructed Binary Time Series

No. 38 (Download full text)

Richard Dennis

Timeless Perspective Policymaking: When is Discretion Superior?

No. 37 (Download full text)

Paul Frijters, Amy Y.C. Liu and Xin Meng

Are optimistic expectations keeping the Chinese happy?

No. 36 (Download full text)

Benno Torgler, Markus Schaffner, Bruno S. Frey, Sascha L. Schmidt and Uwe Dulleck

Inequality Aversion and Performance in and on the Field

No. 35 (Download full text)

T M Christensen, A. S. Hurn and K A Lindsay

Discrete time-series models when counts are unobservable

No. 34 (Download full text)

Adam Clements, A S Hurn and K A Lindsay

Developing analytical distributions for temperature indices for the purposes of pricing temperature-based weather derivatives

No. 33 (Download full text)

Adam Clements, A S Hurn and K A Lindsay

Estimating the Payoffs of Temperature-based Weather Derivatives

No. 32 (Download full text)

T M Christensen, A S Hurn and K A Lindsay

The Devil is in the Detail: Hints for Practical Optimisation

No. 31 (Download full text)

Uwe Dulleck, Franz Hackl, Bernhard Weiss and Rudolf Winter-Ebmer

Buying Online: Sequential Decision Making by Shopbot Visitors

No. 30 (Download full text)

Richard Dennis

Model Uncertainty and Monetary Policy

No. 29 (Download full text)

Richard Dennis

The Frequency of Price Adjustment and New Keynesian Business Cycle Dynamics

No. 28 (Download full text)

Paul Frijters and Aydogan Ulker

Robustness in Health Research: Do differences in health measures, techniques, and time frame matter? 
No. 27 (Download full text)

Paul Frijters, David W. Johnston, Manisha Shah and Michael A. Shields

Early Child Development and Maternal Labor Force Participation: Using Handedness as an Instrument

No. 26 (Download full text)

Paul Frijters and Tony Beatton

The mystery of the U-shaped relationship between happiness and age.

No. 25 (Download full text)

T M Christensen, A S Hurn and K A Lindsay

It never rains but it pours: Modelling the persistence of spikes in electricity prices

No. 24 (Download full text)

Ralf Becker, Adam Clements and Andrew McClelland

The Jump component of S\&P 500 volatility and the VIX index

No. 23 (Download full text)

A. S. Hurn and V.Pavlov

Momentum in Australian Stock Returns: An Update

No. 22 (Download full text)

Mardi Dungey, George Milunovich and Susan Thorp

Unobservable Shocks as Carriers of Contagion: A Dynamic Analysis Using Identified

Structural GARCH

No. 21 (Download full text) (forthcoming)

Mardi Dungey and Adrian Pagan

Extending an SVAR Model of the Australian Economy

No. 20 (Download full text)

Benno Torgler, Nemanja Antic and Uwe Dulleck

Mirror, Mirror on the Wall, who is the Happiest of Them All?

No. 19 (Download full text)

Justina AV Fischer and Benno Torgler

Social Capital And Relative Income Concerns: Evidence From 26 Countries

No. 18 (Download full text)

Ralf Becker and Adam Clements

Forecasting stock market volatility conditional on macroeconomic conditions.

No. 17 (Download full text)

Ralf Becker and Adam Clements

Are combination forecasts of S\&P $\mathbf{5 0 0}$ volatility statistically superior?

No. 16 (Download full text)

Uwe Dulleck and Neil Foster

Imported Equipment, Human Capital and Economic Growth in Developing Countries 
No. 15 (Download full text)

Ralf Becker, Adam Clements and James Curchin

Does implied volatility reflect a wider information set than econometric forecasts?

No. 14 (Download full text)

Renee Fry and Adrian Pagan

Some Issues in Using Sign Restrictions for Identifying Structural VARs

No. 13 (Download full text)

Adrian Pagan

Weak Instruments: A Guide to the Literature

No. 12 (Download full text)

Ronald G. Cummings, Jorge Martinez-Vazquez, Michael McKee and Benno Torgler

Effects of Tax Morale on Tax Compliance: Experimental and Survey Evidence

No. 11 (Download full text)

Benno Torgler, Sascha L. Schmidt and Bruno S. Frey

The Power of Positional Concerns: A Panel Analysis

No. 10 (Download full text)

Ralf Becker, Stan Hurn and Vlad Pavlov

Modelling Spikes in Electricity Prices

No. 9 (Download full text)

A. Hurn, J. Jeisman and K. Lindsay

Teaching an Old Dog New Tricks: Improved Estimation of the Parameters of Stochastic

Differential Equations by Numerical Solution of the Fokker-Planck Equation

No. 8 (Download full text)

Stan Hurn and Ralf Becker

Testing for nonlinearity in mean in the presence of heteroskedasticity.

No. 7 (Download full text) (published)

Adrian Pagan and Hashem Pesaran

On Econometric Analysis of Structural Systems with Permanent and Transitory Shocks and Exogenous Variables.

No. 6 (Download full text) (published)

Martin Fukac and Adrian Pagan

Limited Information Estimation and Evaluation of DSGE Models.

No. 5 (Download full text)

Andrew E. Clark, Paul Frijters and Michael A. Shields

Income and Happiness: Evidence, Explanations and Economic Implications.

No. 4 (Download full text)

Louis J. Maccini and Adrian Pagan

Inventories, Fluctuations and Business Cycles. 
No. 3 (Download full text)

Adam Clements, Stan Hurn and Scott White

Estimating Stochastic Volatility Models Using a Discrete Non-linear Filter.

No. 2 (Download full text)

Stan Hurn, J.Jeisman and K.A. Lindsay

Seeing the Wood for the Trees: A Critical Evaluation of Methods to Estimate the Parameters of Stochastic Differential Equations.

No. 1 (Download full text)

Adrian Pagan and Don Harding

The Econometric Analysis of Constructed Binary Time Series. 